\title{
A escrita da intimidade: o quarto entre o público e privado*
}

\author{
Arthur Prado**
}

É recente o entendimento de que os espaços interiores e os acontecimentos da vida privada merecem a atenção dos historiadores. Em sua História dos Quartos, Michelle Perrot contribui com essa perspectiva ao abordar as relações entre a intimidade e a existência social. Nesse sentido, os quartos individuais ou conjugais, quartos de crianças, de moças ou de operários, são lugares nos quais se materializam espacialmente formas diversas de poder disciplinar, de relações de afeto e de proteção. Além disso, como argumento que percorre o livro todo, o quarto moderno representa o desejo, muitas vezes irrealizável, de ter um espaço só para si.

Nesse livro, Michelle Perrot deu continuidade a motivações que a acompanham desde o início da carreira, quando já tinha a intenção de dedicar-se à história das mulheres. Naquele momento, o interesse nascido da leitura de O Segundo Sexo (1949), de Simone de Beauvoir, não foi acolhido por seu orientador, Ernest Labrousse, que a incentivou a pesquisar as greves operárias ${ }^{1}$, tema considerado de maior interesse na época (Schvarzman, 1995:30). A partir de 1968, com uma importante intensificação do movimento feminista, foi possível inserir na história o ponto de vista dos "invisíveis", dentre os quais Perrot destaca as mulheres. Quanto à história da vida privada, destaca-se sua participação no projeto

\footnotetext{
* Resenha de PerRot, Michelle. História dos Quartos, São Paulo, Paz e Terra, 2011. Recebida para publicação em 1 de novembro de 2012, aceita em 26 de fevereiro de 2013.

** Mestrando do departamento de História (IFCH-UNICAMP). arthur_pprado@yahoo.com.br>

1 De sua tese de doutorado nasceu seu primeiro trabalho, Les ouvriers en grève, publicado em 1974.
}

cadernos pagu (41), julho-dezembro de 2013:449-454. 
dirigido por Georges Duby e Phillipe Ariès. ${ }^{2}$ No volume por ela organizado, nota-se que as questões de gênero engendram um olhar diferenciado sobre o domínio das intimidades $e$ assuntos particulares, tratados como uma "história política do cotidiano" (Perrot, 1993:13). Para a autora as investigações possíveis nesse tipo de abordagem enfrentam muitas dificuldades metodológicas, cuja superação deve muito às contribuições de outros campos das humanidades, "mas talvez ainda mais à reflexão feminista debruçada nesses últimos anos sobre o público e o privado, a constituição das esferas, as relações entre os sexos na família e na sociedade" (id.ib.).

Em História dos Quartos são centrais as diferenças entre os quartos ocupados por homens ou por mulheres, suas relações com esse espaço e as distinções entre os usos masculinos e femininos (por exemplo, em relação à disposição dos móveis e objetos pessoais e sobre quais pessoas podem ser convidadas a entrar). A discussão é pautada pela preocupação com os poderes que, manifestados pela ordem social estabelecida, agem sobre a casa $e$ sobre os corpos. No capítulo dedicado especialmente aos quartos de mulheres, Perrot afirma:

Tudo concorre para encerrá-las aí: a religião, a ordem doméstica, a moral, a decência, o pudor, mas também o imaginário erótico, que senta as mulheres sonhadoras à janela ou as reclina, leitoras lânguidas, mais ou menos despidas sobre um sofá ou um canapé ou uma cama (p.131).

A pesquisa histórica que permitiu esse livro privilegia o período compreendido entre o final do século XVIII e o início do $\mathrm{XX}$, raramente abordando casos fora da França. Seus personagens principais são os grandes escritores do período, cujas vidas dedicadas à escrita pressupõem longas reclusões que têm justamente o quarto como cenário mais apropriado. A autora

2 A História da vida privada foi publicada no Brasil pela Companhia das Letras entre 1990 e 1995, em cinco volumes. 
destaca o ato de escrever como prática própria do movimento em direção à privacidade, cada vez mais acentuado pela visão de mundo dominante da burguesia. Não se trata apenas da produção de romances por Balzac, Proust, Kafka e Virginia Woolf, que investigaram e descreveram os funcionamentos mais íntimos da mente e dos sentimentos humanos, mas também da vida de homens e mulheres comuns, que escrevem cartas e diários. Fundamentalmente como parte da experiência feminina, o diário, muitas vezes escondido em uma gaveta, como uma necessidade de segredo, "é escrito à noite, na solidão do quarto e à luz de uma luminária. Ele não tolera a presença do outro" (p.90). É nesse sentido que a autora enfatiza a inconveniência do quarto conjugal para essa prática, afirmando que, após o casamento, a maioria das mulheres abandona seus diários.

Dentre os quartos de mulheres destaca-se o quarto de Simone de Beauvoir, que "em seus quartos de aluguel, queria sobretudo uma mesa para escrever" (p.163). Essa escritora, tão importante para Michelle Perrot, tem sua trajetória pensada em relação à de seu companheiro, Jean-Paul Sartre, que desprezava o quarto particular, expressão da vida burguesa. Por essa razão o casal trabalhava nos cafés de Paris e vivia em quartos de hotel, onde não era necessário preocupar-se com a propriedade, com o cuidado do lar que, para Sartre, tendia a uma rotina insuportavelmente monótona. Simone de Beauvoir cansou-se dessa vida; ela queria de fato "um quarto para si", e em 1954, após o sucesso de Mandarins, comprou um pequeno apartamento, onde viveu até o fim da vida. Beauvoir recusava "o peso do doméstico e a alienação caseira", mas desejava ao menos um quarto com cozinha e prezava por personalizar o espaço: "Pus cortinas vermelhas nas janelas, comprei luminárias de bronze verde; [...] suspendi nas paredes e na grossa trave do teto objetos trazidos de minhas viagens" (Beauvoir apud Perrot, 2011:164).

Foi dedicado também todo um capítulo aos quartos de hotel, nos quais Jean-Paul Sartre sentia-se livre. Essa sensação era compartilhada por Franz Kafka, que nesse ambiente passageiro 
A escrita da intimidade

escapava à intromissão familiar. "Sua mãe revistava suas coisas. Ele não podia escrever. Isso reforçava sua fobia a contatos" (p.195). Para Kafka, ter a chave de um quarto provisoriamente seu era a conquista de alguma liberdade. Das possibilidades de isolamento e anonimato oferecidas pelos hotéis, Perrot destaca ainda, sob o título "Amor e morte", a oportunidade que esses espaços oferecem para encontros amorosos ilícitos e fugazes, tanto nas hospedarias baratas e pouco limpas, como nos luxuosos Palaces. Ao mesmo tempo, são também lugares em que as pessoas morrem. Causavam preocupação aos hoteleiros da Riviera os hóspedes tuberculosos que decidiam passar ali seus últimos dias. "Os hotéis tinham previsto tudo para a liberação rápida do corpo. No Ritz, uma saída especial devia evitar qualquer encontro entre os vivos e o morto, cujos despojos obscureciam a reputação festiva do palácio" (p.180).

A separação entre vivos e mortos no hotel revela o modo como, do final do século XVIII em diante, posturas disciplinares, cuidados com a higiene e o pudor investiram-se na própria materialidade dos espaços. Essa perspectiva está presente ao longo da História dos Quartos, em que se pode notar a importância do pensamento de Michel Foucault para Michelle Perrot: "Dever-se-ia escrever uma história dos espaços - que seria ao mesmo tempo uma história dos poderes, desde as grandes estratégias da geopolítica até as pequenas táticas do habitat, [...]" (Foucalt apud Perrot, 2011:16). Essa sugestão de Foucault foi aceita nesse livro, com destaque para os quartos de hospital e leitos de morte, as celas dos mosteiros e das prisões. Importante também, nesse sentido, é o tratamento dado ao quarto do rei - antes da Revolução -, espaço detalhadamente ritualizado, sobre o qual a autora discute as cerimônias do despertar e do deitar-se, do vestirse e do despir-se. A disposição de cada elemento tinha função simbólica, e um convite para se aproximar era sinal de privilégio, assim como ultrapassar limites indevidamente significava a profanação do quarto real. Tudo estava relacionado ao poder sagrado que residia no corpo humano do rei. A Medicina 
redimensionou a dupla natureza de Luis XIV doente, e os médicos passaram a ter livre acesso para tratar de sua saúde. "A medicalização do quarto do rei humaniza sua pessoa $e$ dessacraliza seu poder. Ela é um teatro da modernidade" (p.46).

De fato, a Medicina aparece como um saber cuja autoridade é fundamental para a definição dos usos dos quartos. Na trajetória histórica que conduz ao quarto individual, no qual se tem a liberdade de dormir sozinho e escrever sem ser incomodado, deve-se considerar também as preocupações higiênicas em relação à promiscuidade e à transmissão de doenças. "A doença foi, como a devoção religiosa e o nascimento, uma das primeiras causas de individualização do ato de dormir" (p.247). Quanto ao doente terminal, o leito de morte aparece como uma criação recente. Graças à sua capacidade de retardar os efeitos fatais e minimizar as dores causadas pelas doenças, foi o progresso da Medicina que tornou possível acompanhar os últimos dias dos agonizantes. Com isso imagina-se evitar a morte solitária e dar tempo aos vivos para lidarem melhor com a perda. "A morte súbita surpreende, nos faz mergulhar em um desespero ainda mais profundamente ressentido em nossos tempos de morte adiada" (p.240).

Em História dos Quartos, a autora aborda também a condição dos operários, primeiro objeto de pesquisa de sua trajetória acadêmica. Os quartos dos operários não podem ser considerados simplesmente mais uma modalidade de quartos. Antes disso, são consequência de um problema histórico de habitação. Por outro lado, Perrot argumenta que as moradias da classe trabalhadora não são homogêneas e suas condições variam de acordo com sua localização na cidade. Difundiu-se todavia, no imaginário do século XIX, a associação entre moradias operárias e um habitat degradado.

Médicos, filantropos, especialistas em economia social, arquitetos, romancistas, mais tardiamente, fotógrafos, cujo objetivo não é neutro, percorreram essas terras exóticas e nós somos tributários de seu olhar (p.198). 
Orientava a ação sanitária desses personagens não só a Medicina, mas também a moral e os bons costumes, que serviam de parâmetro para identificar formas perigosas de convivência que colocavam em risco toda a sociedade e, portanto, deveriam ser corrigidas.

A partir de uma perspectiva pouco usual - o interior dos quartos -, esse livro discute com profundidade as questões da cultura material, dos espaços de intimidade e do cotidiano. Talvez por conta do avanço dos estudos de gênero e da crise dos grandes paradigmas explicativos, abordagens desse tipo atraem cada vez mais a atenção dos pesquisadores, inclusive no Brasil $^{3}$ desde meados do século XX. É importante reforçar, por fim, o interesse que há em História dos quartos sobre uma história do privado, e mais que isso, da privacidade, marcada por relações de poder, conflitos, desejos e transformações.

\section{Referências bibliográficas}

PERROT, Michelle (org). História da vida Privada 4: da revolução francesa à primeira guerra. São Paulo, Companhia das Letras, 1993.

PerRot, Michelle. História dos Quartos, São Paulo, Paz e Terra, 2011.

SchVARzMAn, Sheila. Entrevista com Michelle Perrot. Cadernos Pagu (4), Campinas-SP, Núcleo de Estudos de Gênero - Pagu/Unicamp, 1995, pp.29-36.

3 Já nos anos 1930, Gilberto Freyre colocou discussões importantes sobre as distinções entre os sexos, sobretudo no sentido de desnaturalizar a fragilidade feminina, produto da dominação e do desejo masculinos no Brasil patriarcal. Para Freyre, a associação entre a mulher e o espaço doméstico deve-se mais a questões culturais, históricas e raciais que a imposições biológicas - embora admita sua existência, sobretudo quanto ao fato da maternidade (Cf. Gilberto Freyre, Sobrados e Mucambos, São Paulo, Global, 2004, 15ªd.). Mais recentemente pode-se destacar a contribuição de Vânia Carneiro de Carvalho, cujo estudo da casa paulistana, no momento em que deixa de ser aristocrática para tornar-se burguesa, permite compreender a cultura material como lugar privilegiado no qual se manifestam relações de poder ligadas a distinções de gênero (Cf. Vânia Carneiro de Carvalho, Gênero e artefato, São Paulo, Edusp, 2008). 